\title{
Reflexiones sobre un Ensayo de sistematización... y otras historias
}

\author{
Guillermo Rosselló Bordoy*
}

En 1978 salía a la luz mi Ensayo de sistematización de la cerámica árabe en Mallorca. ' Culminaba así un largo proceso de investigación iniciado en 1966 al descubrir el yacimiento oculto en el subsuelo del huerto de las religiosas dominicas de Sta. Catalina de Sena en Palma de Mallorca. Un solar inmenso en el interior de la ciudad islámica de Mallorca, la Madîna Mayūrqa. Yacimiento que permaneció intacto desde la fundación del monasterio a mediados del siglo XVII hasta su destrucción en la fecha antes indicada.

La excavación de urgencia, en una época en que no se conocía esta eufemística intervención en el subsuelo urbano, sin presupuesto y sin apoyo institucional, pues la única defensa del excavador era la amenaza de paralización de las obras de urbanización de aquel solar, siguió hasta avanzado el año 1968.

El estudio de materiales pudo hacerse con relativa facilidad mientras la obra civil de lo que sería la sede del Museo de Mallorca se desarrollaba con lentitud exasperante, con interrupciones impuestas por el capricho de algunos capitostes que en aquellos momentos cortaban el bacalao y por tanto el que suscribe contaba con tiempo suficiente para limpiar, restaurar, reintegrar, dibujar y estudiar todo el caudal importante que suponía el verdadero tesoro hallado en una parcela importante de mi ciudad.
Hacia 1976 el trabajo estaba ultimado y a punto de una redacción definitiva. Fue posible esta labor gracias a la ayuda de Juan Camps Coll, que no sólo llevó a cabo los trabajos de campo, sino que realizó la mayor parte de las reconstrucciones del material cerámico; mi padre Francisco Rosselló que pudo entretener sus ocios de jubilado dibujando y reconstruyendo los temas decorativos de la cerámica para, así, dar forma al libro y Bartolomé Payeras Franch, en aquel entonces Secretario General del Instituto de Estudios Baleáricos que quiso que el libro saliera a la luz, usando y tal vez abusando de las prerrogativas que su cargo le confería, pues Secretario General suele ser sinónimo de general secretario, antes y ahora.

Antes de la publicación había tenido ocasión de ofrecer a los interesados ciertos avances sobre mi investigación. Recuerdo entre ellas las I Jornadas de Cerámica del Mediterráneo en Hammamet celebradas en setiembre de 1973. Las actas nunca fueron publicadas, si bien la estancia en Túnez me permitió entrar en contacto con los materiales cerámicos de Raqqada, Qairawān, Sabra Mansūrîya y con la excelente bibliografía que, en aquellos momentos, aun era asequible, desde los antiguos trabajos de Marçais a las publicaciones de carácter etnológico sobre las pervivencias alfareras de Nabeul y Jerba.

\footnotetext{
* Director de Museo de Mallorca.

I ROSSELLÓ BORDOY, Guillermo: Ensayo de sistematización de la cerámica árabe en Mallorca, Palma de Mallorca, 1978.
} 
La versión original de mi comunicación se publicó, en 1985, en las páginas de la revista Mayurqa, entonces portavoz de los estudios de arte, arqueología e historia de la Facultad de Filosofía y Letras de la Universidad de Barcelona, origen de la actual Universidad de las Islas Baleares.

En el Ensayo... pude incorporar otros yacimientos urbanos en particular y rural uno de ellos, que habían proporcionado materiales salvados a la brava, sin intervención coherente, siempre gracias a la buena voluntad de propietarios y contratistas.

El libro apareció semanas después de la clausura del I Coloquio Internacional de Cerámica Medieval del Mediterráneo Occidental celebrado en Valbonne en setiembre de 1978. Un avance del mismo, que pasó sin pena ni gloria, fue presentado a dicho coloquio, publicándose con posterioridad en las Actas de esta primera reunión que tanto significó para los estudios de ceramología medieval. ${ }^{2}$

Esta sería en líneas muy generales la genealogía del tal Ensayo de sistematización... que gracias a los hados benevolentes ha tenido una trascendencia que nunca hubiera imaginado. Trascendencia que se tradujo en una muy rápida desaparición de los circuitos comerciales y, supongo, con ciertos beneficios económicos para el Instituto que lo editó, pues en cierta ocasión el Secretario General de turno (ya no era el amigo Payeras) inició algunas maniobras para que se reeditara. Habían transcurrido siete años y una revisión completa, necesaria por otro lado, no estaba en mi ánimo llevarla a cabo.

Era consciente que aquel estudio necesitaba una revisión a fondo, una autocrítica meditada y las aportaciones de todos los amigos que habían seguido sus directrices, necesariamente tenían que incorporarse a una nueva edición. No era el momento y mi actividad profesional al frente de un Museo que ha sufrido más zancadillas y paréntesis que cualquier otro Museo del mundo, impedían dedicar tiempo y esfuerzos a esta revisión.
Los sucesivos secretarios generales que han seguido gobernando el Instituto no insistieron. ¡Allah sea loado! No tenían noticia del libro y el posible beneficio económico si es que lo hubo, había sido anterior a su gestión. Hoy día el desconocimiento es tal que en los catálogos del Instituto sigue figurando como libro adquirible, para desesperación de distribuidores y libreros.

Han transcurrido veinte años y el Ensayo de sistematizacion... ya es una pieza de museo; de lo contrario no estaríamos reunidos aquí. Se sigue utilizando pero su presencia en las bibliografías cada vez es más tenue. Las jóvenes generaciones de investigadores no han tenido acceso a sus páginas y las cosas buenas, si las hay, se utilizan de oídas y como referencias de segunda, tercera y hasta cuarta mano y en verdad os digo, algunos dislates son de verdadera antología del disparate.

A pesar de lo difícil que supone, a estas alturas de la vida, emprender una autocrítica, es preciso hacerlo. Mejor diría es imprescindible hacerlo, pues mi hipercriticismo con los demás exige una actuación coherente con el mismo y con mi propia obra. $Y$ en este sentido sigo creyendo en aquel viejo aforismo que dice es de sabios rectificar. Aforismo que ha desaparecido de los libros de citas de nuestros políticos actuales que, sin lugar a dudas, desconocen el significado del verbo rectificar.

El Ensayo de sistematización... estaba estructurado en dos partes fundamentales: la primera dedicada a la Clasificación tipológica, y otra a la Decoración y su problemática. Seguían otros aspectos tales como marcas de propiedad, utillaje alfarero, función de las series cerámicas, intento de cronología que no eran más que apuntes previos a los aspectos que los materiales mallorquines sugerían al investigador.

Un apartado de conclusiones y finalmente el inventario de materiales que, hoy día alcanza unos grados de obsolescencia, utilizando la actual jerga televisiva, impresionantes.

2 Las referencias a comunicaciones presentadas al Coloquio que aparecieron en mi libro se hicieron de acuerdo con la edición ciclostilada de las mismas. La edición definitiva se hizo en Paris el año 1982. 
Tal vez el aspecto que mejor se sostiene de mi trabajo sea la clasificación tipológica. En aquel entonces planteaba una estructura formal en base a 17 series distintas. Numero suficiente al alcance de todos para definir, partiendo de la forma de las cosas, su función.

En este aspecto sigo insistiendo que una clasificación para ser operativa debe de ser manejable y posiblemente hoy fuera conveniente reducir este esquema. Algo hice en sentido contrario al publicar en 1983 un articulo sobre Nuevas formas en la cerámica de época islámica ${ }^{3}$ y de modo especial en 1991 al publicar El nombre de las cosas en al-Andalus: una propuesta de terminología cerámica. ${ }^{4}$ Si en 1983 incluía dentro de las series tipológicas dos nuevos elementos: taza y ungüentario-cantimplora, el aporte más interesante consistía en apurar, siempre partiendo de la forma estricta, las variantes establecidas de acuerdo con nuevos hallazgos. En 1991 la tipología se desbordó aunque en mi defensa puedo argüir que gran parte del aumento en cuanto a series formales se debía a ejemplares constatados en la península, sin representación, aun hoy, en las islas orientales de al-Andalus. Así las series aumentaban hasta 39.

¿Era entonces operativo el sistema? Sigo creyendo que la diversificación fue excesiva. Es más cuando André Bazzana ${ }^{5}$ popularizó entre nosotros la simple y neta clasificación de forma abierta - forma cerrada, los aspectos formales para la clasificación de ejemplares cerámicos dejaban de tener interés pues por encima de todo primaba la funcionalidad de éstos y su función se apoyaba en unos condicionantes sociales muy importantes que obligaban a la humanidad a multiplicar su ajuar a medida que sus necesidades culturales así lo exigían. Un ejemplo claro sería la presencia del plato individual a partir del siglo XIII cuando la etiqueta cortesana considera que no es de buen gusto que los alimentos se coman con las manos. El ataifor, zafa, servidora para presentar los manjares no desaparecen pero la cortesía y, por qué no, la higiene impiden servirse directamente de ellos. Recordemos que en el Kitab altabikh ${ }^{6}$ aparece ya una referencia a un mujtaf que sin ser propiamente un tenedor, tal artilugio es más moderno, se utilizaba para un mejor manejo de la carne a la hora de trincharla.

Supongo que la clasificación propuesta en 1978 fue útil, y tal vez su utilidad, tácitamente, se basara en la función que se podría presumir se daba a las cosas, aunque, más bien, pasara casi por alto, pues los aspectos funcionales quedaban reducidos a cuatro:

- servicio de vajilla

- menaje de cocina

- ajuar doméstico

- ajuar agrícola.

$Y$ en aquel entonces y para los materiales mallorquines era más que suficiente. Las complicaciones, a la fuerza, tenían que proceder del cúmulo de materiales que en otros enclaves andalusíes aparecían y con ello añadían una variedad formal realmente atractiva.

Al observar el éxito de mi trabajo me pregunté si tal cosa tenía o no tenía fundamento. Sin duda no existía un trabajo similar anterior, sin duda muchas formas aparecidas en la península no eran copias miméticas de las mallorquinas, mejor dicho de aquellas halladas en Mallorca. Posiblemente el simple aspecto formal poco importaba, sin embargo el valor funcional del objeto cerámico si era de primer orden y era necesario tenerlo en cuenta. Ataifores podía haber muchos, pero siempre tenían una función muy específica: presentar alimentos.

3 ROSSELLÓ BORDOY, Guillermo : "Nuevas formas en la cerámica de época islámica", BSAL, 39, 1983, 237-260.

4 ROSSELLÓ BORDOY, Guillermo: El nombre de las cosas en al-Andalas: una propuesta de terminología cerámica. Palma de Mallorca, 1991.

5 BAZZANA, André: "Céramiques médiévales les methodes de la description analytique appliquées aux productions de l'Espagne orientale. I Les poteries domestiques d'usage courant", Mélanges de la Casa de Velazquez, 15, 1979, I35-185.

BAZZANA, André: "Céramiques médiévales: les methodes de la description analytique appliquées aux productions de l'Espagne orientale. II Les poteries decorées, Chronologie des productions médievales", Mélanges de la Casa de Velazquez, 16, 1980, 57-95.

$6 \mathrm{HUICI}$ MIRANDA, Ambrosio: Traducción española de un manuscrito anónimodel siglo XIII sobre la cocina hispano-magribí, Madrid, 1966, 90-91. 
Recordemos el texto de Ibn Asim el granadino cuando nos cuenta:

y encontró un hombre en una higuera dos albacoras en la más especial calidad como tales y púsolas ambas en un tayfûr, sobre la cabeza de un muchacho, para que las llevara al rey...

El țayfūr o ataifor servirá siempre como fuente de servicio, tanto para regalar los higos al rey como para servir un solemne cuscús.

De todos modos en la sistematización se introdujeron gazapos dignos de una estrepitosa carcajada. Quisiera recordar el más flagrante de ellos referido a una simple ilustración (fig. 22 del libro) donde se apostillaba lo siguiente:

Tapón y cantimplora, tipos excluidos de la clasificación a causa de su representatividad prácticamente nula.

Y tanto el malhadado tapón, que no era tal sino el remate central de un candil paternero de pie alto, cazoleta y múltiples mechas y para mayor vergüenza mía de época cristiana, que no tapaba nada sino que era, simplemente, un asidero para facilitar el transporte de la luminaria, como la cantimplora, pues si en 1978 su representatividad era prácticamente nula, justo castigo a mi perversidad, desde entonces empezaron a proliferar cantimploras a troche y moche, dejándome con un palmo de narices.

Otro aspecto discutible y harto discutido entre discípulos y amigos, si los no amigos han hecho mofa de ello no han tenido la valentía de hacerla en buena lid, fue el incluir dentro de la serie marmita el tipo $\mathrm{E}$, precisamente una de las formas que desde los inicios proporcionó un índice cronológico más exacto, cuando en realidad su función más congruente era la de vaso para beber o mishrab en la terminología del árabe andalusí. Menos mal que la sorna amistosa de muchos de vosotros la bautizó de inmedia- to como marmi-jarra y aunque tal denominación sea poco científica, difícilmente será borrada de los comentarios y chanzas postcongresuales, no en balde parodiando al pobre Francisco I, prisionero en Pavía, podemos decir que todo se ha perdido menos el humor y la vida.

A nivel formal ya manifesté mi extrañeza ante la dificultad de materializar el mihrās o mortero a partir de un espécimen cerámico. Sin duda el ejemplar que definía la serie era inadecuado, pues en realidad se comprobó que era una intrusión cristiana y como tal, fue borrado del mapa; sin embargo no hay, por el momento, un ejemplo claro de al-mihras cerámico atribuible a época islámica. El ejemplar así definido por Helena Kirchner, pese a su parecido con el mortarium de época romana, no acaba de ofrecer una absoluta seguridad en cuanto a su función?

El testimonio del anónimo autor del Kitab altabikh no apoya la existencia de un mortero islámico hecho de barro cocido pues únicamente se refiere al mihrās de piedra mármol, de madera, que ha de ser madera dura tal como la del castaño, terebinto, olivo, fresno, boj o raíz de vid, añadiendo que el mortero de cobre no es adecuado pues enverdece, se altera el contenido de aquello que se ha picado en su interior y se deteriora ${ }^{8}$. Ahora bien el hecho de no citar el mihrās de cerámica no supone que no pudiera existir.

Si atendemos a la morfología de las cosas considero que dentro de la serie ataifor es donde podemos apreciar unos hitos más importantes, tanto desde el punto de vista estético, como formal y funcional. No está de más recordar que la cerámica de época islámica fue coto cerrado para los historiadores del arte y aun, en cierto modo, sigue siéndolo. Un plato de servicio es un soporte adecuado para una bella decoración y en este sentido tales recipientes, reciban el nombre que reciban en todas las épocas, ha tenido una especial importancia para coleccionistas y tratadistas.

\footnotetext{
7 KIRCHNER, Helena: Etude des céramiques islamiques de Shadhfillah (Setefilla, Lora del Río, Sevilla), Lyon, $1990,138$.

8 HUICI MIRANDA, Ambrosio: Traducción española de un manuscrito anónimo...., 90.
} 
Sin embargo a partir del ataifor y sus innúmeras variantes se ha podido establecer una cronología, yo diría que en extremo precisa y un índice de procedencia ajustadamente seguro.

Después del Ensayo... he seguido trabajando en esta cuestión y puede que algún día sea factible sistematizar de una vez por todas estas ideas, hoy un tanto dispersas y no siempre publicadas con el cuidado necesario ?

Si tuviera que resumir ahora el esquema propuesto a nivel tipológico creo que lo escrito en El nombre de las cosas: una propuesta de terminología cerámica sigue siendo válido y a ello me remito.

Un comentario sobre la cuestión, tal vez sarcástico más que irónico: si a lo largo de mi actividad profesional he luchado para buscar un nombre a las cosas, cuando observo que nuevos investigadores, imbuídos por una formación clásica, harto esclerotizada, se dedican a reinventar tipologías basadas en un Rosselló I, Rosselló IV o Rosselló D me siento triste y lleno de frustración. Posiblemente por considerar estas gentes que el tal Rosselló es algo así como un San Dressel o un San Lamboglia que como Gary Cooper está en los cielos, y nada más lejos de la realidad. Quisiera reproducir unas palabras que justificaban mi estudio publicado en 1978 cuando dije:

Las razones de esta terminología estriban en la necesidad de prescindir de términos adoptados en la arqueología clásica por resultar disonantes en un ambiente cultural distinto como es el islámico. Si bien este tipo de investigación arqueológica se halla en sus inicios se ha creído conveniente establecer una seriación que permita desde un primer momento identificar la pieza estudiada sin tener que acudir para su identificación a un término clásico, si bien en muchos aspectos es indudable que el origen formal de las cerámicas estudiadas ha de buscarse en elementos anteriores 10.
Y en este sentido insistía en 199| sobre el mismo tema. Aunque pueda calificarse de batallita senil considero que su repetición hoy, en este lugar y con este motivo especial, es justa y necesaria:

Harto conocida es mi preocupación por dar a la cerámica de época islámica una nomenclatura que permita diferenciar de un modo adecuado los tipos cerámicos hasta ahora identificados. Mis anteriores propuestas, unas aceptadas, otras silenciadas, siempre se han basado en una constante lingüística, presente tanto en castellano como en catalán, apoyada en la gran cantidad de palabras que, en ambas lenguas, tienen un origen árabe y en menor escala beréber. Este tesoro semántico más o menos vigente en el lenguaje actual apoya esta idea, pues la riqueza lingüística de las lenguas romances desarrolladas en España, es suficientemente amplia, para justificar no sólo su utilización en la terminología ceramológica, sino también su puesta en valor, como medio para mantener la fluidez de nuestros idiomas y evitar su empobrecimiento.

Se podría argüir que los sistemas alfa-numéricos, hoy día pueden resultar más operativos y más prácticos a la hora de informatizar nuestros conocimientos, pero es preciso reconocer que el lenguaje de computadora, aparte de su aridez y absoluta monotonia, es poco adecuado e inaceptable para todos aquellos que seguimos considerando que el lenguaje es uno de los grandes tesoros de la Humanidad, la belleza de la palabra es privativa del hombre y su utilización es una forma de creación artística que, desgraciadamente, estamos abocados a dilapidar de forma desconsiderada.

El caudal semántico que ronda en torno al ceramista y sus productos es, de tal modo, sugestivo que el retornar sobre el tema, considero será siempre una tarea enriquecedora. En realidad muchas de estas palabras siguen vigentes, algunas de ellas han perdido su valor

9 La bibliografía posterior a 1978 está recogida en MURILLO, Jaume, RIERA, M. M. y SOBERATS, Natàlia: Sobre ceràmica. Dades per a una bibliografía de la ceràmica a les Illes Balears, Palma de Mallorca, 1997, I09-I I2. [Quaderns de Ca la Gran Cristiana - I2]

10 ROSSELLÓ BORDOY, Guillermo: Ensayo de sistematización, 12. 
original e identifican objetos que no corresponden al objeto que inicialmente fue identificado con una palabra definida; otras, en cambio, han desaparecido del lenguaje coloquial y a pesar de su recesión se han mantenido, posiblemente por inercia, en los elencos oficiales que recogen el caudal léxico de nuestros idiomas, lo cual, a mi modo de ver, da un refrendo a su utilización en el campo científico.

Sigo manteniendo mi idea de que ambos idiomas: el castellano y el catalán, son suficientemente ricos en arabismos, como para buscar elementos extraños a nuestras lenguas y a la cultura material que motiva nuestras investigaciones. Por ello considero absurdo utilizar términos ajenos a nuestras propias lenguas cuando tenemos a nuestro alcance un caudal inmenso en el que nos podemos abastecer sin tener que acudir a préstamos ajenos.

Como es lógico esta opinión es compartida por unos, menospreciada por otros y discutida en ciertas ocasiones, lo cual no deja de ser positivo pues toda controversia genera discusión y de ésta, para bien o para mal, nace la luz. Por ello me siento obligado a reincidir en el tema aun a sabiendas de que mi insistencia llegue a ser pesada y en exceso prolija.

Esta preocupación terminológica se da en otros campos y los intentos desarrollados son siempre positivos. Esclarecedor resulta para mí el artículo de Bádenas y Olmos sobre la propuesta de normalización de la nomenclatura de los vasos griegos y sería deseable que algo similar se pudiera hacer en el campo, extenso y complejo, de las cerámicas de época romana aunque las denominaciones al uso (nombre del estudioso que ha dado a conocer el tipo y número de orden para identificar la variante) hayan alcanzado una aceptación unánime que no es aconsejable obviar, pues ha sido universalmente aceptada.

Posiblemente, insisto, en nuestra época donde la sigla y el esquema alfa-numérico están a la orden del día, el pretender jugar con el puro valor de las palabras sea una extravagancia. Tal vez esto venga impuesto por idiomas de escaso desarrollo, que por razones que no hacen al caso, están mediatizando y oprimiendo a lenguas con una base semántica esplendorosa. El lenguaje de computadora es áspero y la palabra, simple y llana, ofrece una cantidad de sugerencias que nunca podrá ser ahogada por una simple fórmula.

De todos modos el tema es arriesgado y como tal propenso a polémicas y discusiones que pueden alcanzar proporciones enojosas, sin embargo, considero oportuno insistir sobre el tema reforzando en la medida de lo posible las bases que han motivado mi, ya larga, aportación al tema. Debo insistir, por tanto, en lo ya expresado en uno de mis últimos trabajos:

Me consuela pensar que esta opinión mía, expresada años atrás, sea compartida por personas que sin conocer mis trabajos se decantan por una actividad similar y es para mi motivo de satisfacción observar que un Drag. 48 o un Lamb. 8.430 pueda identificarse con nombres tan bellos como olla, caccabus o caccabulus, patina, patella, sartago, etc., etc.

Satisfacción y consuelo pensar que aun quedan gentes en este mundo de locos que prefieren, por menguada que sea, la inteligencia natural, a la tan cacareada inteligencia artificial que pretenden convencernos que es la panacea universal y que buscan el nombre de las cosas en Horacio, Plauto, Lucrecio, por qué no en Apicio, Stacio o Columela, en lugar del nombre de un santón o de un buda inmenso como el de Kamakura y un simple número.

La decoración en cerámica de época islámica es otro aspecto a tratar y tal vez a enmendar respecto a lo que dije hace veinte años.

Quede bien presente que el Ensayo de sistematización... abarcaba un período muy concreto de la vida de Mallorca, en unas condiciones político-económicas que poco tenían a ver con similares vicisitudes en al-Andalus peninsular.

Las Islas fueron incorporadas al estado omeya en 903 y permanecieron bajo la égida del Islam hasta 1229, por lo que respecta a Mallorca; hasta 1235 Ibiza y hasta 1287 Menorca. 
En una etapa previa las incursiones norteafricanas contactaron con las Baleares bizantinas. A raíz de la expedición de 'Abd Allāh ibn Mūsā de 707 que origina un pacto (ahd) intuído, pero no confirmado, a consecuencia del amān que en 849 otorgó el emir 'Abd al-Rahman II. Quede claro, pues, que en las Baleares la cerámica de época emiral no pudo estar representada y, además cabe recordar que la provincia balear nunca tuvo contacto político con el estado visigótico peninsular.

Así pues, la cronología de las cerámicas de época islámica giraba en torno a unas fechas muy concretas que en líneas generales fuera intuición, fuera sonido casual de una flauta en boca de un inexperto, no anduvo muy desencaminada y que por ahora se puede mantener con justeza, salvo pequeños retoques puntuales.

Así podemos observar que la moda del verde y manganeso primó a lo largo del siglo $X$ y durante todo el XI. En 1978 no podíamos documentar la elaboración de este tipo de cerámica pues la única referencia, el testar de la Casa Desbrull, no tenía el peso suficiente para asegurar tal producción, pese a sus evidencias pues era un hecho único que, en estricta probidad científica, necesitaba de otras comprobaciones. Al menos para mí cuando observo que de una simple prospección se descubren fases nuevas de la historia de mi tierra.

Hoy es problema resuelto y gracias a los hallazgos de Pisa y a las evidencias claras de hornos en la misma Madina Mayūrqa, esta fabricación queda perfectamente asegurada y se puede afirmar que la cruzada pisano-catalana de | | |4- | | | 5 puso fin a esta actividad artesana.

Tal vez dentro de este momento la profusa decoración mallorquina: geométrico vegetal con tendencia a cubrir todo el espacio susceptible de ser decorado, sea lo más característico. La posi- ble expansión fuera de la isla de esta manufactura que tendría como soporte el vaso de perfil quebrado (Ataifor II), característica de lo mallorquín, documentada en el Norte de Africa y con cierta presencia entre los hallazgos valencianos merece ser estudiada, por cuanto la relación con Pisa está suficientemente demostrada.

Hoy podemos atribuir al momento almohade un renacimiento en la producción cerámica a base de las grandes tinajas (khabiyät o alfábies en mi catalán de Mallorca) con decoración impresa que podemos individualizar con cierta facilidad gracias a estudios recientes. Al tratar de las khabiyāt menorquinas tendría que destacar un aspecto mas entre los calificables de error garrafal entre las afirmaciones, tal vez dogmáticas de mi Ensayo... Me refiero a las khabiyàt de Menor$\mathrm{ca}$, dadas a conocer por Camps y Mercadal " en 1914 y popularizadas por Millas Vallicrosa en un artículo publicado en Al-Andalus ${ }^{12}$. En repetidas ocasiones he seguido esta idea ${ }^{13}$. Aun a pesar de las dificultades de interpretación de los textos garabateados por una mano poco hábil, consistentes en inscripciones espontáneas grabadas, de manera tosca, en la superficie de las grandes tinajas. Por estar grabadas después de la cochura no podía tratarse de una marca de fábrica. La gran cantidad de ellas aun en servicio en Menorca, era otro misterio. En un principio consideré que se trataba de ejemplares fabricados en aquella isla, entre su infeudación a la Corona de Aragón en 1232 y su definitiva conquista en 1287.

Esta idea hay que descartarla por completo pues morfológicamente tales tinajas son producto de los alfares de Jerba y Nabeul, muy posteriores al breve período independiente de Menorca musulmana. Sin duda llegaron en tiempos modernos a la isla vecina como medio elemental de un transporte, posiblemente de granos, comercio esencial para la supervivencia de los habitantes de aquella tierra. Es un error más que añadir al cúmulo de despropósitos.

I I CAMPS I MERCADAL, Francesc: "Tinajas de la época árabe menorquina", RdeM., 1912, 35-42

12 MILLAS VALLICROSA, José M: "Jarras menorquinas con inscripción árabe", Al-Andalus, 22, 1957, 4074I0.

I3 ROSSELLÓ BORDOY, Guillermo: "Corpus balear de epigrafía árabe, Mayurqa, 13, 1975, 6-68

ROSSELLÓ BORDOY, Guillermo: "Nuevos epígrafes espontáneos en tinajas árabes menorquinas", Homenaje a Samuel de los Santos, Albacete, 1988, 235-238. 
Error, en verdad, compartido con otros investigadores ${ }^{14}$, aunque ello no sirva de excusa.

Queda un hueco en nuestros conocimientos. Es la falta de información sobre la producción característica del siglo XII que podemos cubrir de modo puntual y para una zona concreta con los materiales fabricados en los alfares de Denia. Hueco que se manifiesta tanto a nivel formal como decorativo y de momento de difícil solución.

Si realmente hubo algo positivo en mi trabajo fue precisamente el incentivar la investigación en toda la geografía andalusí, pues antes de su publicación las monografías sobre cerámica de época islámica se reducían a unas pocas decenas de fichas, que no está de más recordarlas de modo sucinto.

En esta revisión he dejado de lado aquellos trabajos que fueron realizados bajo criterios estrictamente artísticos, prescindiendo además de las ambiguedades que giran en torno a denominaciones tales como hispano-morisco, hispano-mudéjar y otras que en aquellas épocas se aplicaban más bien a las producciones de reflejo metálico de época cristiana, introduciendo una confusión semántica poco congruente.
La lista se inicia en 1888 con el estudio de D. Manuel Gómez Moreno González, el pintor, según la denominación familiar que describe puntualmente el hallazgo de Atarfe, la supuesta Medina Elvira granadina ${ }^{15}$. Tengamos bien presente que este título encabezará toda la bibliografía especializada.

Hasta principios de siglo no habrá una continuidad conseguida gracias a los trabajos de Ricardo Velázquez Bosco, ahora olvidados y que sería preciso reivindicar de alguna manera, pues inauguraba la serie de arquitectos excavadores del mundo islámico y la atención prestada a la cerámica es de veras fundamental ${ }^{16}$.

En 1924 Don Manuel Gómez Moreno Martínez, hijo del autor anteriormente citado y, sin exageración alguna, el padre de la arqueología medieval española ve publicada la conferencia pronunciada en la Universidad de Barcelona ${ }^{17}$. Es el primer intento de síntesis que tendrá continuidad con otras obras del mismo autor publicadas a lo largo de su dilatada vida (195I) 18. Síntesis que servirá de pauta a otros autores que posteriormente realizarán obras similares como Manuel González Martíl', Leopoldo Torres Balbás ${ }^{20}$, Lluís Llubiá 21 , Vicente Maestre 22 y finalmente Juan Zozaya Stabel-Hansen ${ }^{23}$.

I4 BERNAT MOLL, Juan de C. de Nicolás i Mascaró: "L'alfàbia islàmica de Said Mazzuz de Mussptà", Programa de festes de Sant Climent, Sant Climent, 1987, s. p.

I5 GOMEZ MORENO GONZALEZ, Manuel: Medina Elvira, Granada, 1888.

16 VELÁZQUEZ BOSCO, Ricardo: Arte del califato de Córdoba. Medina Azzahra y Alamiriya, Madrid, 1912.

VELÁZQUEZ BOSCO, Ricardo: Excavaciones en Medina Azahara. Memoria sobre lo descubierto en dichas excavaciones, Junta Superior de Excavaciones y Antigüedades, 54, Madrid, 1924.

17 GOMEZ MORENO MARTINEZ, Manuel: Cerámica Medieval Española, Barcelona, 1924.

I 8 GOMEZ MORENO MARTINEZ, Manuel: "Cerámica, Arte árabe español hasta los almohades", Ars Hispaniae, 3 Madrid, I95।, 310-323.

19 GONZALEZ MARTÍ, Manuel: Cerámica Española, Barcelona, 1933.

GONZALEZ MARTÍ, Manuel: Cerámica del Levante Español Loza, Barcelona, 1944.

20 TORRES BALBÁS, Leopoldo: "De cerámica hispano-musulmana, Al-Andalus, 4, 1939, 4I2-432.

TORRES BALBÁS, Leopoldo: "Arte Almohade. Arte nazarí. Arte mudéjar:, Ars Hispaniae, 4, Madrid, 1949.

2 I LLUBIÁ, Luis Ma: Cerámica medieval española, Barcelona, 1967.

22 MAESTRE, Vicente: La cerámica hispano musulmana, Barcelona, 1971.

23 ZOZAYA STABEL-HANSEN, Juan: "Problemática de la arqueología medieval posterior al siglo VIII", Crónica C. N. A, II, I968, 846-849. ZOZAYA STABEL-HANSEN, Juan: " Ensayo de una cronología para ciertos tipos de cerámica califal andalusi", La Céramique Médievale en Méditerranée Occidentale (Sophia Antipolis, 1978), II, s.p.

ZOZAYA STABEL-HANSEN, Juan: "Aperçu géneral sur la céramique espagnole" La Céramique Médiévale en Méditerranée Occidentale (Sophia Antipolis, 1978), II, s.p. 
Al-Zahrā' será en todo el largo período que transcurre entre 1912 y 1978 el yacimiento más destacado y el que mereció mayor atención, al menos a nivel arquitectónico, pues los estudios ceramológicos no alcanzaron cotas muy elevadas de atención, pese a que en todas las memorias se reprodujeron los principales hallazgos de este tipo. He citado antes los trabajos de Velazquez Bosco, sin duda los más interesantes desde nuestro punto de vista. A éstos siguieron otras memorias redactadas por los diferentes miembros de la Comisión de Excavaciones encargada de los trabajos científi$\cos ^{24}$. El catálogo de piezas desplazadas al Museo Arqueológico Nacional redactado por Emilio Camps Cazorla ${ }^{25}$ para finalizar con las diferentes intervenciones de Basilio Pavón en la década de los sesenta 26 .

Visiones puntuales, dedicadas a yacimientos o territorios concretos que no tenían la proyección de al-Zahra' tambien aparecen tempranamente en esta relación inaugurado con los trabajos de Cayetano de Mergelina sobre Bobastro ${ }^{27}$ y en Baleares donde un perdido artículo de periódico escrito por Rafael de Ysasi Ransome daba a conocer un pieza emblemática hallada en los niveles superiores de la ciudad romana de Pollentia ${ }^{28}$. A este trabajo, que pasó totalmente desapercibido siguieron otras intervenciones como la de A. Mulet en $1938{ }^{29}$ y la más tardía de Millás Vallicrosa sobre las controvertidas tinajas menorquinas ${ }^{30}$. La actuación posterior ya corresponde a mi propia actividad ${ }^{31}$ y en 1972 se incorporaron a la investigación balear Juan Zozaya, Manuel Fernández Miranda y Alfonso Moure ${ }^{32}$.

Un interés especial merecen los trabajos de Manuel Esteve Guerrero ${ }^{33}$ el cual enfrascado en la búsqueda de Tartessos supo tratar con cuidado especial los niveles superficiales de Mesas de Asta que proporcionaron una importante información sobre un establecimiento musulmán, fechable en el siglo XII. La actitud de Esteve Guerrero, insólita en su época, no ha

24 GIMÉNEZ AMIGO, R., RUÍZ MARTíNEZ, E., CASTEjÓN, R. y HERNÁNDEZ JIMÉNEZ, F.: Excavaciones en Medina Azahra. Córdoba, Madrid, 1926.

CASTEJÓN, R. y MARTíNEZ DE ARIZALA: Excavaciones del Plan Nacional en Medina Azahara (Córdoba), Madrid, 1945.

25 CAMPS CAZORLA, Emilio: "Cerámica y vidrios de Medina Azzahra (Córdoba)", Adquisiciones del Museo Arqueológico Nacional (1940-1945), Madrid, 1942, I48-I54.

CAMPS CAZORLA, Emilio: "Cerámica musulmana de Córdoba", Adquisiciones del Museo Arqueológico Nacional (1940-1945), Madrid, 1942, I54-161.

26 PAVÓN MALDONADO, Basilio: Memoria de la excavación de la mezquita de Medinat al Zahrá, Madrid, 1966, 121-125.[Excavaciones Arqueológicas en España 50]

PAVÓN MALDONADO, Basilio: "Notas sobre la cerámica hispano-musulmana:, Al-Andalus, 32, 1967, 4I5-437.

PAVÓN MALDONADO, Basilio: "La loza doméstica de Madinat al Zahrá"', Al-Andalus, 37, 1972, 191-227.

27 DE MERGELINA, Cayetano: Excavaciones de Bobastro (Málaga), Madrid, 1927.

28 Un curioso [de Ysasi Ransome, Rafael ]: "Una interesante vasija agarena", Correo de Mallorca, Palma, 2 mayol936

29 MULET, A.: "Los recientes hallazgos de cerámica en Palma", BSAL, 27, 1938, 169-180.

30 MILLAS VALLICROSA, José M: "Jarras menorquinas con inscripción árabe", Al-Andalus, 22, 1957, 407-4I0.

31 ROSSELLÓ BORDOY, G.: "Hallazgos cerámicos en el 'Colegio de Montesión' (Palma de Mallorca)", AlAndalus 29, 1964, 329-336. ROSSELLÓ BORDOY, G.: "La arqueología musulmana en Mallorca:Estado de la cuestión", BAEO, 6, 1970, I53-I 64.

ROSSELLÓ BORDOY, G.; CAMPS COLL, J.; CANTARELLAS CAMPS, Catalina :"Candiles musulmanes hallados en Mallorca, Mayurqa, 5, |97|, |33-16|.

ROSSELLÓ BORDOY, G.: "Cerámica califal descoberta a Mallorca", Mallorca musulmana (Estudis d'arqueologia), Palma, 1973, I73- 182. ROSSELLÓ BORDOY, G.: "Excavaciones arqueológicas en Palma de Mallorca. Sondeos practicados en la antigua Casa Desbrull", Noticiario Arqueológico Hispánico. Arqueologia, II, 1974, I35- 47.

ROSSELLÓ BORDOY, G.: "La Cerámica árabe en Mallorca", Mayurqa, I4, 1975, 215-230.

ROSSELLÓ BORDOY, G.: Decoración zoomórfica en las Islas Orientales de al-Andalus, Palma, 1976.

ROSSELLÓ BORDOY, G.: "La céramique arabe a Majorque (Problemes chronologiques)", La Céramique Médiévale en Méditerranée Occidentale (IX-XV Siécle) Sophia Antipolis, 1978, II, s. p. [La edición delinitiva es Paris, 1982).

32 ZOZAYA, Juan; FERNÁNDEZ MIRANDA, Manuel; MOURE, Alfonso: "El yacimiento medieval de Almallutx (EscorcaBaleares), Noticiario Arqueológico Hispánico. Arqueología, I, 1972).

33 ESTEVE GUERRERO, Manuel: "Excavaciones de Asta Regia (Mesas de Asta, Jerez). Campaña de 1942-1943", Acta Arqueológica Hispánica, III, Madrid, 1945.

ESTEVE GUERRERO, Manuel: "Mesas de Asta", Memorias de los Museos Arqueológicos Provinciales, Madrid, 1945.

ESTEVE GUERRERO, Manuel: "Excavaciones de Asta Regia (Mesas de Asta, Jerez). Campaña de 1945-1946", Informes y Memorias, 22, Madrid, 1950.

ESTEVE GUERRERO, Manuel: "Nuevo hallazgo de cerámica árabe en Mesas de Asta (Jerez)", Al-Andalus, XXV, 1960,200-203. 
merecido la atención debida por cuanto aportó unos materiales excepcionales, hoy magníficamente expuestos en el Museo Municipal de Jerez, que apenas han sido estudiados. Autory obra son merecedores de un estudio en profundidad pues a través de la información aportada podríamos alcanzar una pauta para adentramos en el mundo, harto desconocido, de las cerámicas del siglo XII. Mesas de Asta, Denia, posiblemente Málaga y Mértola podrían ser las vías de acceso necesarias para entrar en la cuestión.

En Córdoba no podemos olvidar los meritorios trabajos de Samuel de los Santos Jener ${ }^{34}$, - los llevados a cabo sobre materiales granadinos por Joaquina Eguaras y Jesús Bermúdez Pareja ${ }^{35}$. Igual podríamos decir de Almería gracias a los esfuerzos de Ochotorena ${ }^{36}$ primero y luego Dorothea Duda ${ }^{37}$ que luego se decantaría por otros temas de investigación. Toledo y Murcia, de la mano de Manuel Jorge Aragoneses ${ }^{38}$, se incorporan pronto a esta línea de investigación y mucho después Julio Navarro continuó la labor emprendida en esta última ciudad ${ }^{39}$, al igual que Valencia gracias a Bazzana y Guichard ${ }^{40}$ y Ceuta, donde las investigaciones de Carlos Posac ${ }^{41}$, uno de los pioneros en este campo, aportaron un información puntual necesaria para ulteriores investigaciones.

La investigación en estos momentos comienza a vislumbrar cómo la influencia del Islam en los territorios septentrionales de la Península Ibérica, incorporados en fechas tempranas a la órbita cristiana tuvo más implantación de lo que se creía. Un caso especial sería el de Balaguer, dado a conocer por Diez Coronel ${ }^{42}$ y después por Dorothea Duda ${ }^{43}$, o Soria gracias a Zozaya ${ }^{44}$ y Alcalá la Vieja de la mano de Manuel Casamar ${ }^{45}$.

Es de justicia destacar que a lo largo de estos años fueron los compañeros del Cuerpo Facultativo de Conservadores de Museos los que dedicaron una atención puntual a un tipo de investigación que, salvo Gómez Moreno y Mergelina, estuvo desatendida de manera sistemática por la Universidad española. Por fortuna esta anómala situación ha cambiado. Buena prueba de ello la tenemos precisamente en esta convocatoria hecha por la Universidad de Jaén y en otras anteriores convocadas por diferentes departamentos universitarios que con su dedicación obvian el abandono propio de otros tiempos. Nombres como los de Eguaras, Santos

34 DE LOS SANTOS JENER, Samuel: "Cerámica pintada musulmana", Memorias de los Museos Arqueológicos Provinciales, 8, 1947, 96- I06. DE LOS SANTOS JENER, Samuel: "Adquisiciones del Museo Arqueológico de Córdoba", MMAP., 9- I0, 1948- I949, 57-60 DE LOS SANTOS JENER, Samuel: "Estampillas de alfarerías monscas cordobesas", MMAP, 9- I0, 1948-1949, 220

35 EGUARAS IBÁÑEZ, Joaquina: "La cerámica de Elvira", MMAP, 6, 1945, 73-77. BERMÚDEZ PAREJA, Jesús: "Quemadores de perfumes en la Alhambra", MMAP, I3- |4, 1953, 42-50. CASAMAR, Manuel: "Notas sobre cerámica del ajuar nazarí:, Al-Andalus, XXIV, 1959, I89- 196.

36 OCHOTORENA, Fernando: "Cerámica árabe de Pechina", MMAP, I3- I4, I952-1953, I26-I 34.

37 DUDA, Dorothea: .Spanisch-Islamische Keramik aus Almería von 12 bis. 15. Jahrundert, Heidelberg, 1970.

38 JORGE ARAGONESES, Manuel: "Dos especieros mudéjares de barro cocido del Museo Arqueológico de Toledo", AlAndalus, XXII, 1957, 191-194. JORGE ARAGONESES, Manuel: Museo de la muralla árabe de Murcia, Madrid, 1966, 123-144.

39 NAVARRO PALAZÓN, Julio: "Cerámicas esgrafiadas con decoraciones antropemórficas". La céramique mádiévale en Méditerranée Occidentale (Sophie Antipolis, 1978), II, sin.

40 BAZZANA, André; GUICHARD, Pierre: "Céramiques communes médiévales de la région valencienne:, La Céramique mádiévale en Méditerranée Occidentale. (Sophia Antipolis, 1978), II, sin.

4 I POSAC I MON, Carlos: "Cerámica con decoración zoomorfa hallada en Ceuta", Atti del III Congresso di Studi Arabi e Islamici (RaveIlo, 1966), Napoli, 1967, 565-567. POSAC I MON, Carlos: "Loza dorada nazarí hallada en Ceuta", IV Congresso de Estudos Arabes e Islámicos (Coimbra-Lisboa, I963), Leyden, 1971, 565-567.

42 DÍEZ CORONEL I MONTULL, Luis : "La alcazaba de Balaguer y su palacio árabe del siglo XI", Ilerda, 29, $1969,335-354$.

43 DUDA, Dorothea: "Keramik und Glass funde auf der Burg von Balaguer", Christian Ewert: Islamische Funde in Balaguer und die Aljafaria in Zaragoza, Berlin, 1971, 251-268.

44 ZOZAYA STABEL-HANSEN, Juan: "Cerámicas islámicas del Museo de Soria", BAEO, I I, 1975, I 35 - I48.

45 CASAMAR, Manuel: "Cerámica musulmana en la fortaleza de Alcalá la Vieja", Al-Andalus, XXIII, I958, 106 - 107. 
Jener, Bermúdez, Camps Cazorla, Jorge Aragoneses fueron los precursores y gracias a ellos nuestros esfuerzos tuvieron un punto de partida. Sean mis palabras un homenaje a los compañeros de un colectivo de magníficos profesionales, desmembrado y aniquilado por una administración que ha convertido los Museos españoles en algo ridículo.

La preocupación por el pasado islámico a través de los ajuares cerámicos no atendió en exclusiva al territorio andalusí, determinados investigadores se preocuparon tambien por el estudio de la proyección de las cerámicas andalusíes fuera de la geografía propia y su expansión hacia Oriente. Kühnel, Gamal Mehrez y Manuel Casamar ${ }^{46}$ en especial aunque en el caso de los dos primeros la confusión entre lo andalusí y lo hispano-musulmán o mudéjar es patente. El estado de la investigación forzosamente tenía que inducir a estas incongruencias.

Realmente es una cosecha menguada para 90 años de investigación, aunque la importancia de algunos de estos estudios primerizos sea cabal, pues en todos ellos hubo siempre un intento de analizar el utillaje cerámico bajo parámetros fuera del campo de las artes.

Por otro lado no ha de extrañarnos tal escasez pues el conocimiento de la cerámica islámica extra-andalusí había seguido unas directrices similares. No es ahora el momento de entrar en esta materia, tan sólo recordar que salvo muy escasa excepciones 47 la mayoría de estudios sobre cerámica de época islámica seguía los parámetros propios de la historia del arte.

Dentro de este repaso de las publicaciones anteriores a 1978 no he mencionado los dos artículos fundamentales de André Bazzana, pues en realidad aparecieron en 1979 y 1980, pese a que la labor de investigación se hizo paralelamente a la mía. No habíamos entrado nunca en contacto y supe de su existencia en Valbonne, cuando nuestros trabajos estaban en prensa. Sin lugar a dudas una relación científica previa habría disipado, de manera mutua, muchas dudas y por lo que a mi respecta habría sido altamente provechosa.

De un total de 62 entradas anteriores a la publicación de mi libro a la cosecha actual hay un mundo impenetrable que tendríamos que acotar a base de hitos especiales como aquellos que señalan las carreteras de montaña invadidas por la nieve. Valbonne (1978), Toledo (1982), Siena (1986), Lisboa (1990), Rabat (1994) en lo tocante a congresos específicos de cerámica medieval. Huesca, Madrid, Oviedo, Alicante por lo que respecta a los Congresos de Arqueología Medieval Española. Aun así la labor se ha convertido en una aventura pues la actual atomización administrativa de España hace que la búsqueda del estudio impreso sea más difícil que el hallazgo de la dichosa aguja en el pajar. La proliferación de monografías en las diferentes comunidades actuales nunca va acompañada de una distribución y difusión ágil y ante tal exagerado aumento editorial es imposible abarcar todo lo publicado.

Desaparecida de la circulación la veterana AlAndalus que gracias a su Crónica Arqueológica de la España Musulmana fue durante muchas décadas la única revista abierta a la investigación medieval de época islámica, la nómina de publicaciones actuales es copiosa y como tal prácticamente inabarcable. De las antiguas revistas el Bolletí de la Societat Arqueológica Lul-liana

46 KÜHNEL, Ernst: "Loza hispano árabe excavada en Oriente", AlAndalus, 7, 1942, 253-268.

MEHREZ, Gamal: "Recientes hallazgos de cerámica andaluza en Alejandría", Al-Andalus, XXIV, I959,

CASAMAR, Manuel: "Fragmentos de jarrones malagueños en los Museos de El Cairo", Al-Andalus, 26, 1961, I85-190.

ZOZAYA STABEL-HANSEN, Juan: "El comercio de al-Andalus con Oriente", BAEO, 5, 1969, 19I-200.

47 MARÇAIS, Georges: Les poteries et faiances de la Qal'a des Beni Hammâd (X-XI siécle). Contribution a l'etude de la céramique musulmane, Constantine, 1913, 399-400.

AL-FARADJ AL-'USH, Abu: "Al-fajjâr gayra al -math mm 'ahwad al 'arabiya al- islamiya fi al-Ma tial al. Watani bi Dimisk", Annales Archaeologiques Syriennes, Damasco, 1961.

GOLVIN, Lucien: Recherches archeologiques á la Qal'a des Banú Hammad, París, 1965, 185-232.

ROSEN-AYALON, Myriam: Villes royales de Suse IV. La céramique islamique, Paris, 1974.

ABD AL-AZIZ Daoutlatli: "La céramique ifriqiyenne du IX siecle au XV siécle", La céramique médiévale en Méditerranée Occidentale (Sophia Antipohs, 1978), I, s. p. 
(1885) con más de cien años de antigüedad sigue en la brecha $y$, por razones obvias, sigue prestando aun hoy una especial atención a la arqueología andalusí.

En cambio el Boletín de la Real Academia de la Historia apenas fue proclive a la problemática arqueológica. Las revista universitarias, básicamente dedicadas todas ellas a la prehistoria y arqueología clásica solo de manera esporádica han abierto sus páginas a este tipo de investigación. De igual modo las series Excavaciones Arqueológicas en España (1962-1994) y Noticiario Arqueológico Hispánico (1952-1988) han pasado a mejor vida y en verdad hay que reconocer que su atención al tema fue muy importante. No en balde el creador de la primera de las series comentadas fue el profesor Gratiniano Nieto, impulsor eficiente de nuestra investigación, persona que además normalizó la segunda de las series indicadas. Su desaparición no ha tenido contrapartida pues en las taifas actuales no se ha considerado oportuno reanudar este tipo de publicaciones, salvo en alguna taifa ilus- trada dirigida por personas competentes en la materia. Recordemos que tener competencias en materia de cultura no significa que aquellos que las han recibido sean competentes.

Sin embargo el espíritu ahorrativo del Ministerio de Cultura, o como se llame hoy, ajeno a la investigación en nuestro solar y abocado a las investigaciones en suelo extranjero, ha tenido sus compensaciones pues pone a nuestro alcance información en territorios foráneos que nos ilustran debidamente sobre temas inverosímiles, probadamente alejados de nuestros problemas. Siempre con alguna brillante excepción como la memoria sobre la cerámica de Gerasa ${ }^{48}$ que al menos nos ilustra medianamente sobre la cerámica bizantina, aunque sean unos materiales harto alejados de los nuestros.

Sirvan estas palabras mías, harto prolijas y en exceso largas, de resumen de unos veinte años de investigación que considero altamente positiva, que sin vuestra dedicación y esfuerzo hubiera resultado baldía. Gracias.

48 Uscatescu, Alexandra: La cerámica del 'macellum' de Gerasa (Yaras, Jordania), Madrid, 1996. 